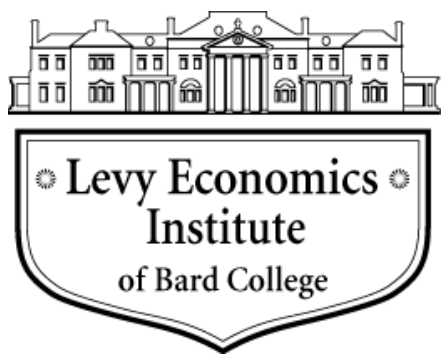

Working Paper No. 967

\title{
Quality of Statistical Match Used in the Estimation of the Levy Institute Measure of Time and Income Poverty (LIMTIP) for Italy 2008 and 2014 and Preliminary Results
}

by

\author{
Erica Aloè \\ Sapienza University of Rome
}

September 2020

The Levy Economics Institute Working Paper Collection presents research in progress by Levy Institute scholars and conference participants. The purpose of the series is to disseminate ideas to and elicit comments from academics and professionals.

Levy Economics Institute of Bard College, founded in 1986, is a nonprofit, nonpartisan, independently funded research organization devoted to public service. Through scholarship and economic research it generates viable, effective public policy responses to important economic problems that profoundly affect the quality of life in the United States and abroad.

\author{
Levy Economics Institute \\ P.O. Box 5000 \\ Annandale-on-Hudson, NY 12504-5000 \\ http://www.levyinstitute.org
}

Copyright (C) Levy Economics Institute 2020 All rights reserved

ISSN 1547-366X 


\begin{abstract}
This paper assesses the quality of the statistical matching used in the LIMTIP estimates for Italy for 2008 and 2014. The match combines the 2008-9 and 2013-14 Italian Time Use Survey (IT-TUS) with the Italian data collected for the European Survey on Income and Living Conditions (IT-SILC) in 2009 and 2015. After the matching, the analysis of the joint distributions of the variables shows that the quality is good.

The preliminary results of the LIMTIP estimates in Italy display widespread time poverty, which translates into significant hidden poverty. The LIMTIP also reveals that the increase in the poverty rate between 2008 and 2014 was even higher that what standard poverty measures report.
\end{abstract}

KEYWORDS: Statistical Matching; Time Use; Household Production; Poverty; LIMTIP; Italy

JEL CLASSIFICATIONS: C14; C40; D31; J22 


\section{INTRODUCTION}

This paper presents the stages of the construction of the synthetic datasets created for estimating the Levy Institute Measure of Time and Income Poverty (LIMTIP) for Italy in 2008 and 2014. The estimation of LIMTIP requires information about the household, its income, and the use of time by its members. All these pieces of information are not present in a single dataset, thus, a synthetic data file has been created by statistically matching two source datasets. I use the Italian Time Use Survey (ITTUS), Indagine Multiscopo sull'Uso del Tempo ${ }^{1}$ for 2008-9 and 2013-14 for time use data and the Italian data (IT-SILC) from the European Survey of Income and Living Conditions (EU-SILC) ${ }^{2}$ of 2009 and 2015 for the information on demographics and income.

The second section of this paper describes the datasets, compares their demographic characteristics, and explains how I constructed corresponding variables in the two datasets, as well as how I undertook the matching; the quality of the statistical match is then assessed. In the third section, preliminary results for Italy's LIMTIP are introduced.

\footnotetext{
${ }^{1}$ The Italian Institute of Statistics (ISTAT) regularly collects data on time use since 2002. The IT-TUS is carried out every five years and is composed of three questionnaires: the individual questionnaire contains general information on family members and their household, the daily diary records the daily use of time of all members ages three years or older, and the weekly diary records the hours of paid work for all employed household members. Individuals are required to fill randomly in the daily diary for weekdays, Saturdays, and Sundays. Sample weights are used to obtain statistics representative of the whole Italian population. The IT-TUS survey contains a great deal of information regarding the household use of childcare and adult care. Activities are classified in 10 groups: physiological needs, professional work, education activity, household activities, voluntary work in organizations and beyond, social life and entertainment, sport and recreation activities, personal hobbies, using mass media, and time spent on moving and transportation. This classification enables a detailed analysis of the time each household member spends on each activity. The IT-TUS does not include information on income and earnings.

${ }^{2}$ EU-SILC is Eurostat's multi-dimensional dataset focused on income but at the same time covering housing, labor, health, demography, education, and deprivation to enable a multidimensional approach to social exclusion to be studied. It consists of primary (annual) and secondary (ad hoc modules) target variables. The primary target variables relate to either household or individual (for persons ages 16 and over) information and is grouped into areas. At the household level it is grouped by basic/core data, income, housing, social exclusion, and labor information; at the personal level it is grouped by basic/demographic data, income, education, labor information, and health. The secondary target variables are introduced every four years or less frequently only in the cross-sectional component.
} 


\section{STATISTICAL MATCH USED FOR IMPUTING TIME USE}

The LIMTIP methodology entails the need of collecting information on the population's income and time use. For this reason, the first step in applying the LIMTIP is that of creating an ad hoc dataset that contains all the information required. In order to obtain this result, I applied the matching algorithm developed at the Levy Economics Institute (Zacharias 2011).

The IT-SILC represents a valuable source of data on income and living conditions of the population, but it is not able to tell much — or anything at all—about the amount and the division of unpaid care and domestic work in the household. In order to have information about the household, its income and the use of time by its members, I created a synthetic data file by statistically matching two data sources. I used the IT-SILC of 2009 and 2015 for the information on demographics and income ${ }^{3}$ and the IT-TUS of 2008-9 and 2013-14 for time use data.

Particularly, the LIMTIP is interested in observing the number of hours of unpaid care and domestic work performed by a household's members. Therefore, I grouped domestic activities in three categories: to provide unpaid care for household members (care); to source necessary goods and services from outside the household (procurement); and to carry out unpaid domestic work (core). Specifically, care relates to all caring activities for other members of the household, as eldercare and childcare, but also, for example, the time spent taking children to school. Procurement represents all those activities that involve buying or obtaining all necessary goods and services, like food shopping or going to the post office to pay the bills. Core includes domestic work such as cleaning, laundering, cooking, etc. All these three categories are grouped under the set of household production. Moreover, I computed time for personal maintenance, which includes sleeping, eating, and personal hygiene, and time for commuting from work to home and vice versa.

The imputation for time use is conducted using propensity score statistical matching (PSSM). PSSM is used in observational studies to generate suitable control groups that are similar to the treatment groups when a randomized experiment is not available (Rubin and Thomas 1996). In the imputation context, the propensity score estimates the "likelihood/probability" of "having the outcome observed" for any

\footnotetext{
${ }^{3}$ For IT-SILC, I selected years 2009 and 2015 because the survey uses the previous calendar year as the income reference period.
} 
subject with a similar background measured by the independent variables. The target variable is regressed on common variables in both files and the predicted value is used to rank the records in each file (Kum and Masterson 2010). Subjects with close propensity scores are considered similar and are matched together. The procedure adopted for the PSSM is the nearest neighbors matching. The intuition behind this procedure is to assign to each individual who performs unpaid care work in the ITSILC the time use of the individual observed in the IT-TUS with the closest characteristics. To make matching feasible, two conditions must hold: (i) the two surveys must be random samples of the same population; and (ii) there must be a common set of conditioning variables in the recipient and donor datasets. In this case, the first condition is satisfied, since both IT-SILC and IT-TUS datasets are randomly selected from the Italian population. The second condition is also satisfied after some recoding of the common information in the datasets.

Once this common set of characteristics is chosen and propensity scores computed, observations in the IT-SILC are matched with observations in IT-TUS, controlling for all their relevant observable background characteristics. The matching is explained step by step in the following subsections.

\subsection{Data and Alignment}

Both IT-TUS and IT-SILC are representative at the national level and contain information for individuals for all age classes. IT-TUS 2008-9 has 44,605 observations, representing 59,426,798 individuals when weighted, while IT-SILC 2009 has 51,196 observations, representing 60,108,862 individuals when weighted. IT-TUS $2013-14$ has 44,866 observations, representing $60,410,793$ individuals when weighted, while IT-SILC 2015 has 42,987 observations, representing 60,843,061 individuals when weighted.

In order to match the most similar observations, I had to select several variables. Following the example of Masterson (2014), I identified a number of strata variables that are relevant for determining the average amount of household production that is required to subsist at the poverty level of income. For this reason, the reference group for household production threshold estimations consists of households with at least one nonemployed adult to avoid underestimation of the necessary amount of household production. Strata variables at household level include: the number of children and of adults; the presence of a nonemployed adult; and the income category. At individual level they also include sex and employment status. Additionally, other variables might be relevant, for example, age, 
citizenship, region of residence, level of education, etc. These additional variables are selected on the basis of their comparability in the two data files.

I extensively worked on the two separate files in order to align the common variables in terms of definition and measurement. For example, in the IT-TUS the only income information present is the main source of income at the individual level. Therefore, based on the categories provided by the variables in the IT-TUS, I constructed a corresponding variable in the IT-SILC where, instead, I found detailed information about different sources of income, both at the household and individual level. I proceeded according to this principle until I harmonized all the definitions of strata and relevant variables.

To maximize the matching quality, I checked that the distributions of the common variables were comparable. I expected comparable distributions because both datasets have a large number of observations and they are both nationally representative. When common variables did not align, I doublechecked the definitions and harmonized them where possible. I found excellent comparability for all the selected variables (see table A1 and A2 in the appendix). After the harmonization, I adjusted the sum of the attached weights for records to make them comparable.

\subsection{Matching}

At this point I need to transfer the variables related to time use from the IT-TUS to the IT-SILC. Considering which of the factors mainly affected the variation in the amount of unpaid care and domestic work, I divided the reference group into 12 subgroups based on the number of children $(0,1$, 2 , and 3 or more) and the number of adults $(1,2$, and 3 or more).

According to the selected strata variables (number of children in the household, number of adults in the household, presence of a nonemployed adult in the household, marital status, presence of children under 3 years of age in the household, sex, main source of income, activity status, and number of earners in the household), I separated the data within each file into 38,400 discrete cells. 
Then I carefully selected the common variables in the logistic regression model for propensity scores to maximize the explanatory power. In the end, my selection of relevant variables included, beside the strata variables: age, level of education, being enrolled in education, having a second job, citizenship, region, household tenure (homeowner versus renter), head of the household, and spouse. ${ }^{4}$

After running the model, all records for each file were sorted by estimated propensity score and attached weight. For every recipient in the recipient file (IT-SILC), an observation in the donor file (ITTUS) was matched with the same or nearest neighbor based on the rank of their propensity scores. In this match, a penalty weight was assigned to the propensity score according to the size and ranking of the coefficients of strata variables not used in a particular matching round (see tables A3 and A4 in the appendix). Under this sorting scheme, I assigned records with larger weights in the donor file to multiple records in the recipient file until all their weight has been used up.

\subsection{Test of Quality of Matching}

In order to check the quality of the matching, I compared the marginal and joint distributions in the matched file and donor file (see tables A5-A8 in the appendix). The constraints of the matching scheme should lead to identical marginal distributions and the joint distribution of variables not jointly observed should be nearly the same.

I checked that the mean and median values for the transferred variables by each strata variable were similar in the matched and donor files. Specifically, I checked if there were discrepancies in time devoted to unpaid care and domestic work by type of household and sex of the individual. The ratio of the average time spent by women and men for different household activities in the matched file to the average value in the donor file and the distribution of weekly hours of unpaid care and domestic work for each of the 12 cells, differentiated by number of adults in the household and number of children in the household (see figures A1-A4 in the appendix), give confidence that the marginal distributions have been well-preserved in the statistical matching process. Divergences are related to the limited number of observations with three or more children.

\footnotetext{
${ }^{4}$ I refer to head of the household as to the person who responded to the survey and to the spouse as their partner.
} 


\section{LIMTIP ESTIMATES FOR ITALY}

The first step for assessing the LIMTIP is to calculate the time deficit at an individual level. To estimate time deficits, ${ }^{5}$ we require information on:

1. weekly hours of required personal maintenance and nonsubstitutable household production;

2. weekly hours of required substitutable household production;

3. actual weekly hours the individual spends on income generation; and

4. required weekly hours of commuting. ${ }^{6}$

With this information I built the thresholds for all the categories, excluding the time spent in income generation, where I use the actual number of hours. The hours of required personal maintenance were estimated as the sum of minimum necessary leisure time (assumed to be equal to 14 hours per week ${ }^{7}$ ) and the weekly average of the time spent on essential activities of personal care. The method assumes that the hours of nonsubstitutable household activities are equal to seven hours per week. ${ }^{8}$ The resulting estimates from the IT-TUS data are shown in table 1. The line labelled "total" is the estimate of the weekly hours of required personal maintenance and nonsubstitutable household production and applies uniformly to every adult.

\footnotetext{
${ }^{5}$ See Zacharias (2011).

${ }^{6}$ If it is applicable.

${ }^{7}$ It should be noted that 14 hours per week was approximately 20 hours less than the mean value of the time spent on leisure (sum of time spent on social and cultural activities, entertainment, sports, hobbies, games, and mass media). The LIMTIP methodology sets the threshold at a substantially lower level than the observed value for the average person in order to ensure that it does not end up overestimating time deficits due to high thresholds for minimum leisure.

${ }^{8}$ It is not possible to determine from the data how much of the household production is nonsubstitutable. For this reason, and in order to be able to compare the results from this study with the results obtained in previous studies, I decided to adopt the seven-hour threshold used in previous LIMTIP studies, which means one hour per day for each adult person in the household. Further research could improve the estimates of the nonsubstitutable household production both from the point of view of the total amount of weekly hours and from one of the sharing among the household's members.
} 
Table 1: Thresholds of Personal Maintenance and Nonsubstitutable Household Activities (weekly hours, persons aged 18 years old and up, Italy 2008 and 2014)

\begin{tabular}{crr}
\hline \multicolumn{2}{c}{$\mathbf{2 0 0 8}$} & $\mathbf{2 0 1 4}$ \\
\hline Personal maintenance & 90.8 & $91.6^{9}$ \\
\hline Personal care & 76.8 & 77.6 \\
\hline Sleep & 57.2 & 57.3 \\
\hline Eating and drinking & 13.6 & 13.9 \\
\hline Hygiene and dressing & 6.0 & 6.4 \\
\hline Necessary minimum leisure & 14.0 & 14.0 \\
\hline Total & 7.0 & 7.0 \\
\hline
\end{tabular}

Source: IT-TUS 2008 and 2014

The hours of required household production depend on the household-level threshold of household production and the individual's share in the household-level threshold. The thresholds for household production hours are set at the household level; that is, they refer to the total weekly hours of household production to be performed by the members of the household, taken together. In principle, they represent the average amount of minimum required household production. In order to identify the minimum required amount of household production, the LIMTIP takes as a standard the average time spent in household production of those households that have an income around the poverty line $\mathrm{e}^{10}$ (income \pm 25 percent of the poverty line). Therefore, the minimum required household production is the household production that is required to subsist at the poverty level of income. Moreover, as mentioned above, the reference group in constructing the thresholds consists of households with at least one nonemployed adult. This is done because, in general, income poverty thresholds used in poverty assessments rest on the implicit assumption that households around or below the poverty line possess

\footnotetext{
${ }^{9}$ The change in the average time spent for personal maintenance registered between 2008 and 2014 might be due to a real change in time use or to a change in how the variables for time devoted to sleep/eat/hygiene were registered or assembled. In fact, when computing the values for these categories it was impossible to find identical variables in the two datasets.

${ }^{10}$ The poverty line is fixed at the threshold defined by Eurostat. Eurostat considers everyone living in a household that stands below the 60 percent of the median equivalized disposable income at risk of poverty. Household equivalized disposable income is calculated as follows:

Equivalized household size $=1+\left(0.5^{*}\right.$ number of persons 14 years old and over $)+\left(0.3^{*}\right.$ number of persons below 14 years old)

Equivalized disposable income $=$ total household disposable income $/$ equivalized household size.
} 
the required number of hours to spend on household production (Zacharias, Antonopoulos, and Masterson 2012).

The estimate of necessary household production is based on the sum of the average time devoted to three forms of unpaid care and domestic work. On the basis of household composition (number of adult members and number of children), the minimum necessary household production to subsist with an income around the poverty line was calculated using the matched dataset. We must use the matched dataset here because the IT-TUS does not include information about the disposable household income, which, as mentioned above, is necessary to determine the household production that is required to subsist at the poverty level of income. The results are presented in figure 1.

Figure 1: Minimum Weekly Hours of Household Production by Number of Adults and Number of Children (Italy, 2008 and 2014)

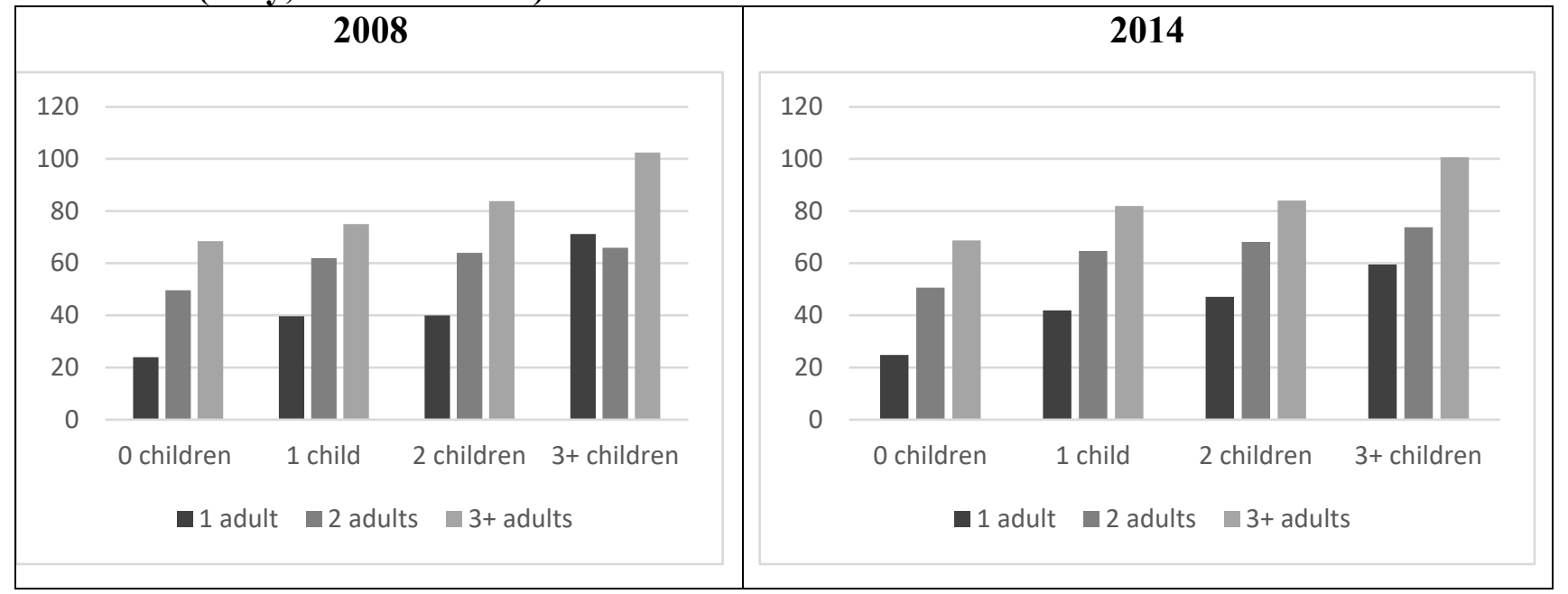

Source: matched datasets

Lastly, I derived the required time for commuting from the time use survey. The exploratory analysis showed that the hours of employment have an important impact on the hours of commuting. Therefore, it did not seem appropriate to use the average time for employees without taking account of the hours of employment. After analyzing how commuting time varies in relation to the hours of work, I determined the average commuting time for persons working less than 30 hours per week and the average commuting time for persons working 30 or more hours. Estimates showed that the average 
commuting time is around three hours per week for employees working less than 30 hours per week, and around four hours per week for those working 30 or more hours. ${ }^{11}$

With the information derived as described above I was then able to estimate the time available at the individual level. The total number of hours in a week is 168 . From the total number of weekly hours I subtracted the weekly hours of required personal maintenance and nonsubstitutable household production, the personal share of weekly hours of required substitutable household production, ${ }^{12}$ and, for employed persons, the weekly hours of paid work and the required weekly hours of commuting. Therefore, individual time deficits for adults (18 years old and up) are obtained. If the sum of paid and unpaid work is higher than the time available (the time left after personal maintenance and nonsubstitutable household production are fulfilled), the person suffers from time poverty.

The first significative result of this analysis is that, in Italy women suffer from time poverty more than men. As shown in figure 2, in 2008, 21.2 percent of women were time-poor versus 12 percent of men. In 2014, the percentage of time-poor women remains approximatively the same, 20.8 percent, but the percentage of time-poor men increased to 14.5 percent. Therefore, a considerable shrinking (almost 3 percentage points) of the gap in time poverty between women and men has been registered. But it was only marginally due to a decrease in time poverty among women, and mainly due to an increase of time poverty among men. ${ }^{13}$ Considering only employed adults, the analysis highlights that the majority (more than 55 percent) of employed women are time-poor. That is around double the time poverty rate registered for employed men (20.6 percent in 2008 and 26.7 percent in 2014). Again, data shows that

\footnotetext{
${ }^{11}$ Estimates for 2008 and 2014 are very close, proving that we can adopt these thresholds for commuting with a good degree of confidence. In 2008, the weekly average commuting time was 2.8 hours for employed persons working less than 30 hours per week and 4.1 for those working 30 or more hours per week. For 2014 the weekly average commuting time was, respectively, 3.1 and 4 hours.

${ }^{12}$ After I estimated the threshold hours of household production, I determined the share of hours of household production of each individual in the household. This was done using the matched data. The method assumes that the share of an individual in the threshold hours would be equal to the share of that individual in the observed total hours of household production in their household. Consider the hypothetical example of a household with only two adult persons, a woman and a man. If the synthetic data show that the two persons spent an equal amount of time in household production, I divide the threshold value of 50 hours of household production that I have for households with two adults and no children equally between them. ${ }^{13}$ The increase in time poverty among men could be due to different elements (an increase in the amount of hours of paid work, an increase in men's share of household production, that could be due to a change in households composition, for example). To disentangle the causes that are at the origin of this phenomenon, a specific analysis is needed but it goes beyond the scope of this work.
} 
for employed women time poverty did not change considerably over the period under analysis, ${ }^{14}$ while for employed men data registered an increase in the incidence of time poverty.

Figure 2: Percentage of Time-Poor Individuals by Gender and Employment Status (persons 18 years and older, Italy, 2008-14)

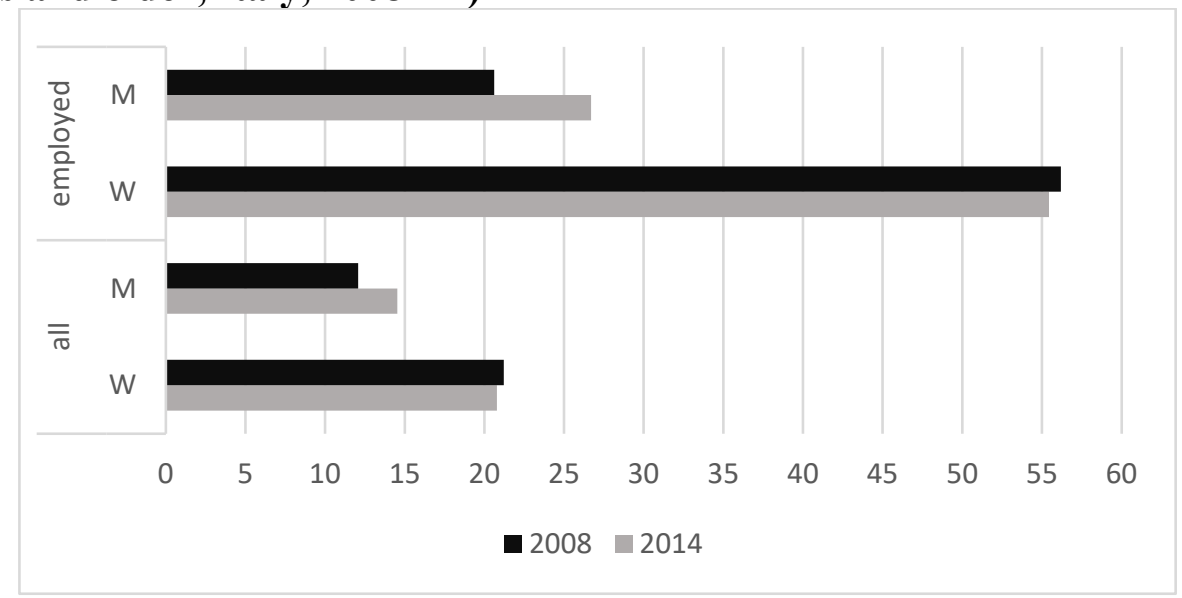

Source: Matched datasets

The results on time poverty in Italy are in line with the findings registered for the countries in previous LIMTIP studies. First, time poverty concerns almost only employed persons. Second, the poverty rate among women is always higher.

The LIMTIP framework allows for the analysis of another type of time poverty, too. This occurs when the time available to the individual, even before taking into account their hours of employment, turns out to be negative. The LIMTIP study on three Latin American countries found that in Argentina and Mexico, such individuals (almost entirely women) made up roughly 20 percent of all the time-poor while in Chile they constituted a smaller fraction at 13 percent (Zacharias, Antonopoulos and Masterson 2012: 54). This type of time poverty can be thought of as a "housework time-bind" because it results exclusively from the higher burden of household production that falls upon women. In Italy, only between 3 percent and 4 percent of time-poor adults are not in employment (4.2 percent in 2008 and 3.4 percent in 2014), but nine out of ten of them are women (92 percent in 2008 and 90.3 percent in 2014).

${ }^{14}$ Nonetheless, for women, in particular, the burden of time deficits became heavier in 2014 compared to 2008. 
Coming back to our LIMTIP estimates on Italy, the household-level value of time deficits can then be obtained in a straightforward manner by summing the time deficits of individuals in the household. First, I designated the household as time-poor if at least one of its members is time-poor. I proceed by calculating a new poverty threshold that considers time deficits. Accounting for time deficits requires the modification of the official poverty threshold. ${ }^{15}$ The modification consists of adding the monetized value of the household's time deficit to the threshold. As a replacement cost of the forgone household production that accompanies the time deficits, I took the hourly minimum pay for domestic workers in Italy, which is equal to 6 euro (including taxation). ${ }^{16}$

In the context of this two-dimensional measure, being time-poor can affect the income poverty status of the individual and their household. As a consequence, high-income families can use their income for covering their time deficits by purchasing market substitutes (e.g., restaurant meals and housekeeper services), while low-income families may not be able to afford them, at least to the extent that the wealthier can. The monetized value of time deficits can raise the poverty line to an extent that some of those who are above the official poverty threshold can now be seen to be poor. For those that are already below the official poverty line, time deficits can make their income deficit (i.e., the difference between poverty line and income) larger.

Standard poverty analysis highlights that 19.7 percent of Italians were at risk of poverty in 2014, representing an increase in the incidence of poverty by almost two percentage points from 2008 (when it was equal to 17.95 percent). But if we take into account time deficits and the ability to purchase market substitutes, 23.3 percent of the population lived in a poor household (see figure 3 ). When the new poverty threshold is introduced, 3.6 percent of the population moves below the poverty line. This phenomenon is called "hidden poverty," because if we do not take into account the necessary household production and the time that it requires, the condition of these persons looks good enough to statistics. Therefore, it should be noticed that between 2008 and 2014, not only the percentage of

\footnotetext{
${ }^{15}$ See Zacharias (2011).

${ }^{16}$ The minimum wage for domestic workers is established by the Contratto Collettivo Nazionale di Lavoro sulla Disciplina del Rapporto di Lavoro Domestico. I use the minimum hourly wage for noncohabiting domestic workers at A level (the lowest), which is equal to 4.57 euro. I then sum the contribution and taxation and I approximate the total to 6 euro. I decided to use the minimum wage in order to avoid overestimation of poverty. The Contratto Collettivo Nazionale di Lavoro sulla Disciplina del Rapporto di Lavoro Domestico is available at: https://www.assindatcolf.it/wpcontent/uploads/2018/06/CCNL-15X21-Assindatcolf-2018.pdf
} 
persons at risk of poverty increased (from 17.95 percent to 19.7 percent), but also the percentage of the hidden poor rose (from 3.1 percent to 3.6 percent).

Figure 3: Percentage of Individuals Living in Poor Households (Italy, 2008-14)

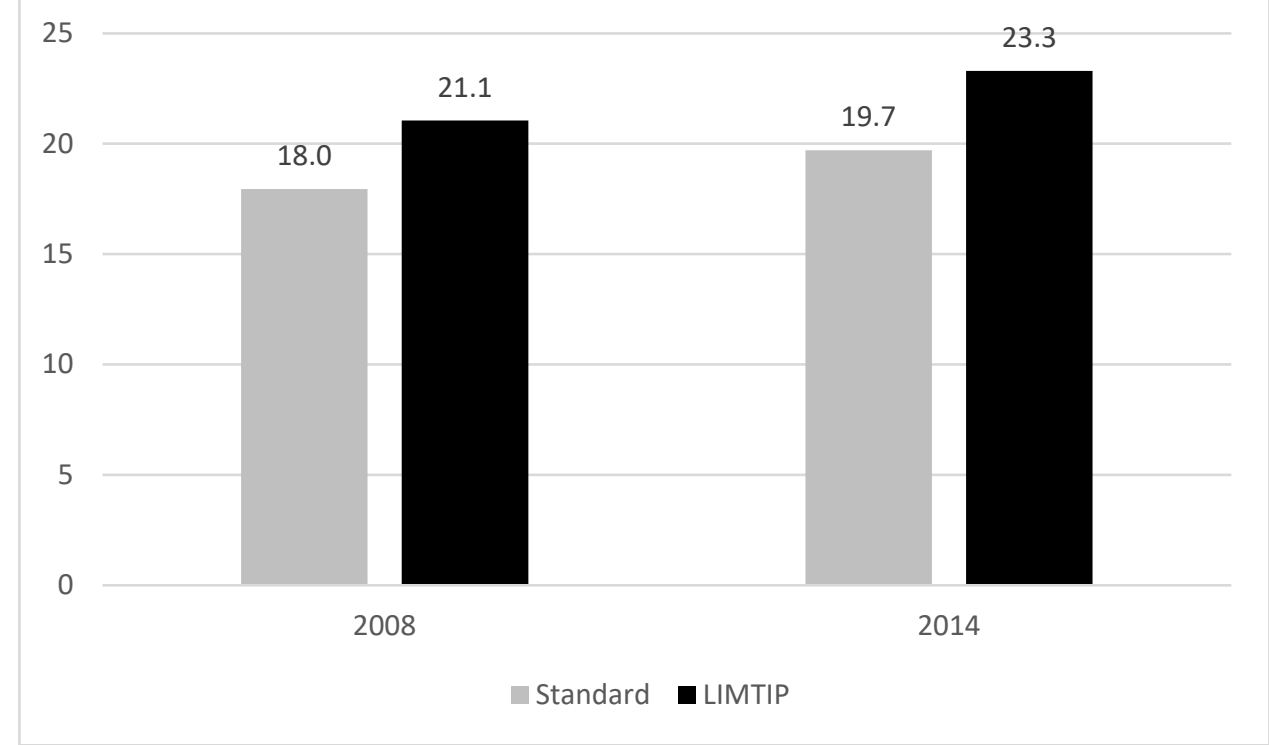

Source: Matched datasets

From a gender perspective, in Italy more than half of the persons who live in a poor household are women (around 55 percent). This result is confirmed both by standard poverty measures and by the LIMTIP.

The LIMTIP analysis translates individual time deficits into household shortfalls. The analysis of poverty at the household level (see figure 4) highlights a result similar to the analysis at the individual level. The LIMTIP shows that more households than those reported by standard poverty measures face poverty. In Italy, hidden poverty among households was equal to 2.4 percent in 2008 and 3 percent in 2014. Again, the LIMTIP shows that between 2008 and 2014, poverty increased more than what was perceived by the traditional poverty measure. 
Figure 4: Percentage of Poor Households (Italy, 2008-14)

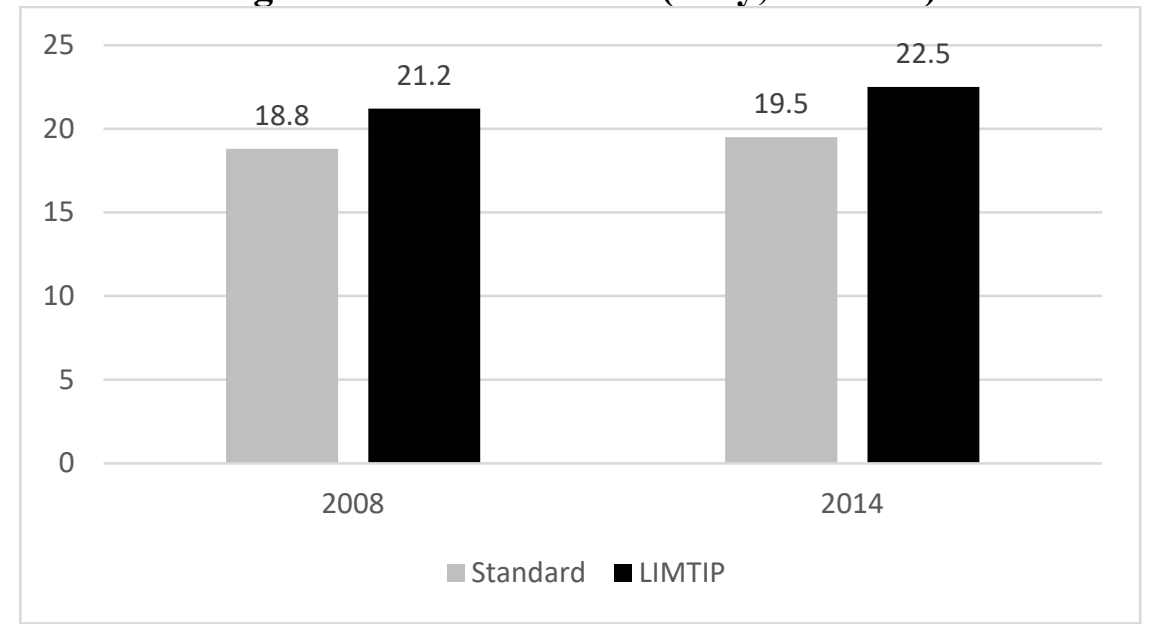

Source: Matched datasets

When we make a comparison with the other countries analyzed under the framework, it emerges that hidden poverty in Italy looks smaller than in previous examples. This might be because, in order to minimize problems of overestimation, the minimum price for the replacement cost of time deficits was adopted in this case, while, as a general rule, the LIMTIP methodology assumes that the replacement cost of time deficits is equal to the average hourly rate of a domestic worker. This decision impacts the poverty threshold. Despite the use of this conservative parameter, the analysis still highlights a higher poverty rate than standard poverty measures.

If we focus on the depth of poverty (see figure 5), data highlight that when we use our new adjusted poverty threshold, the depth of poverty is considerably larger. In 2008, persons at risk of poverty were on average around 2,900 euro below the poverty line, but when we use our new adjusted poverty threshold, poor persons were, on average, almost 3,200 euro below the poverty line. In 2014, the depth of poverty increased. Persons at risk of poverty averaged around 3,500 euro below the poverty line, while poor persons below the LIMTIP poverty threshold averaged around 3,800 euro below the line. 
Figure 5: Average Income Deficit by Poverty Threshold (Italy, 2008-14)

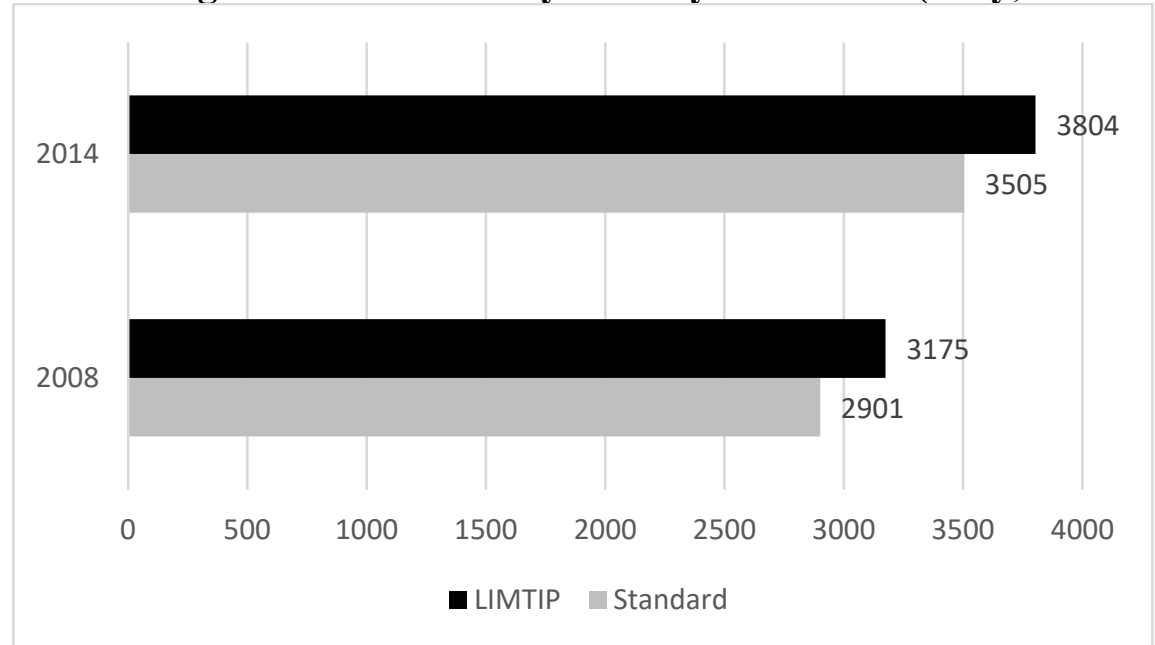

Source: Matched datasets

The depth of poverty is strongly connected to the household composition. Even if standard poverty measures are able to highlight a difference between households with children and households without children in terms of depth of poverty, they underestimate it. Between 2008 and 2014 there was a rise of poverty, both in terms of the number of the poor households (as shown above) and in terms of the magnitude of the poverty these households suffer. The estimates show that, in 2014, the average monthly income deficit for households with children was almost 1.1 times higher than the official income deficit—4,005 euro compared to 3,654 euro (figure 6). 
Figure 6: Average Income Deficit by Poverty Threshold and Type of Household (Italy)

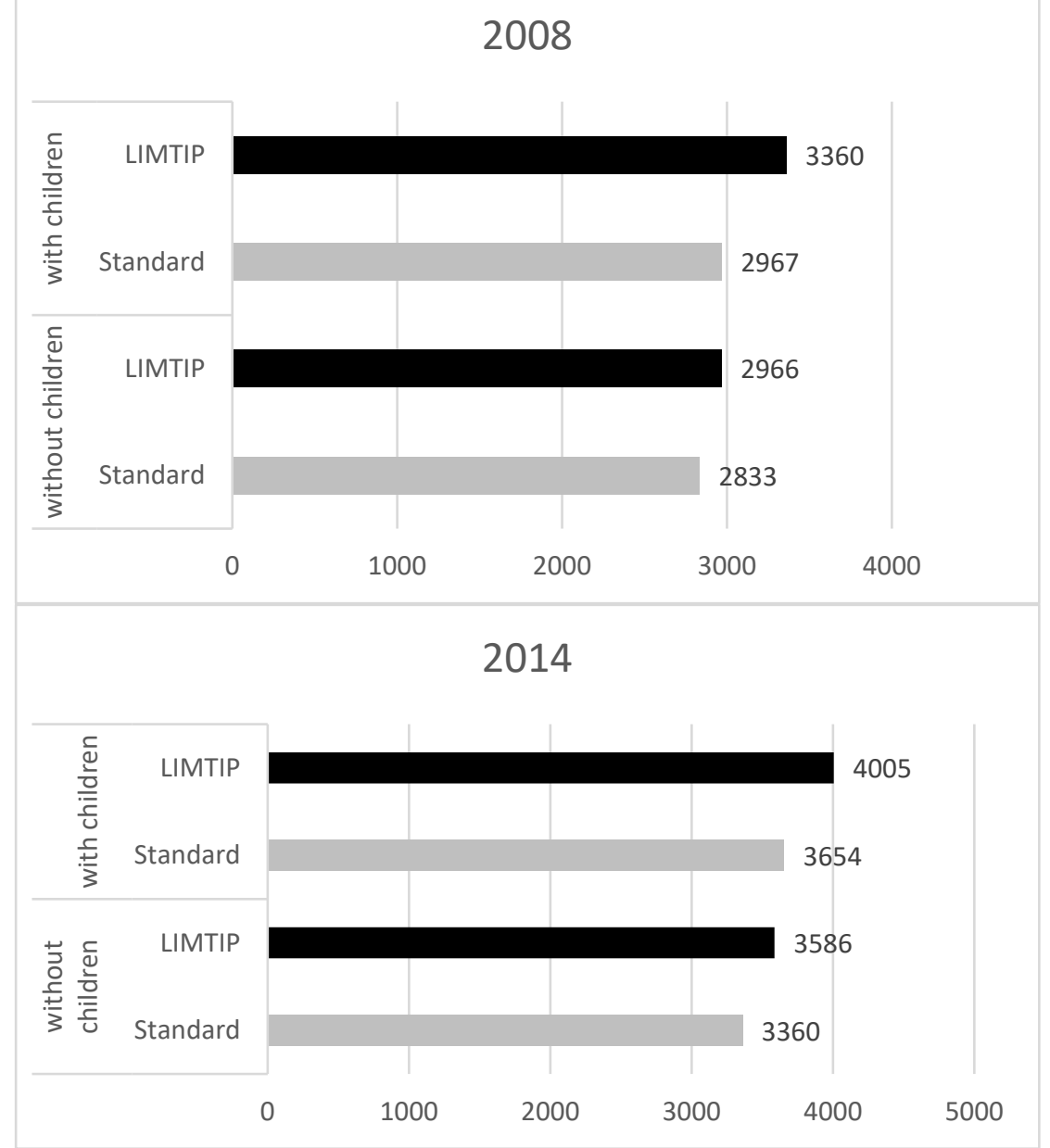

Source: Matched datasets

Finally, the LIMTIP allows us to distinguish among four poverty categories: income- and time-poor households; income-poor households; time-poor households; and nonpoor households. Figure 7 highlights this distinction and confirms the relevance of household composition. Among households that do suffer from neither time nor from income poverty, around 85 percent are households without children, while households with children represent the majority among the time- and income-poor (around 65 percent). 
Figure 7: Households with or without Children by LIMTIP Category (Italy, 2014)

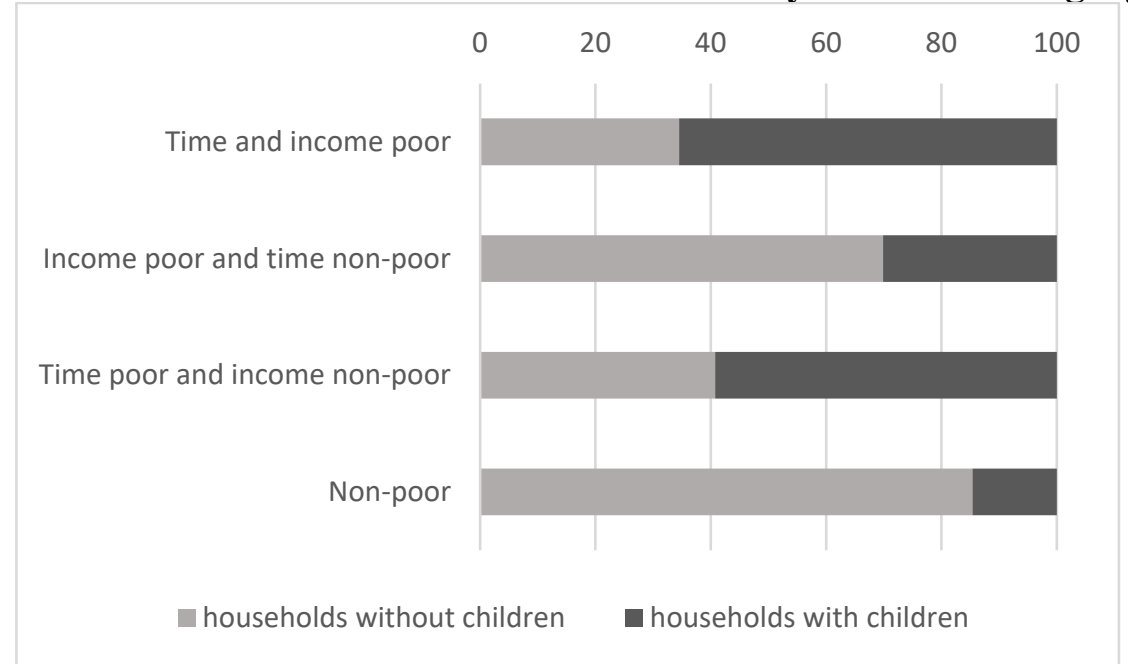

Source: matched datasets

If we look at the distribution of households by the four LIMTIP categories (figure 8), we notice that between 2008 and 2014 the percentage of income non-poor households decreased, while the percentage of time- and income-poor household increased $(+1.24$ percent $)$.

Figure 8: Percentage of Households by LIMTIP Category (Italy, 2008 and 2014)

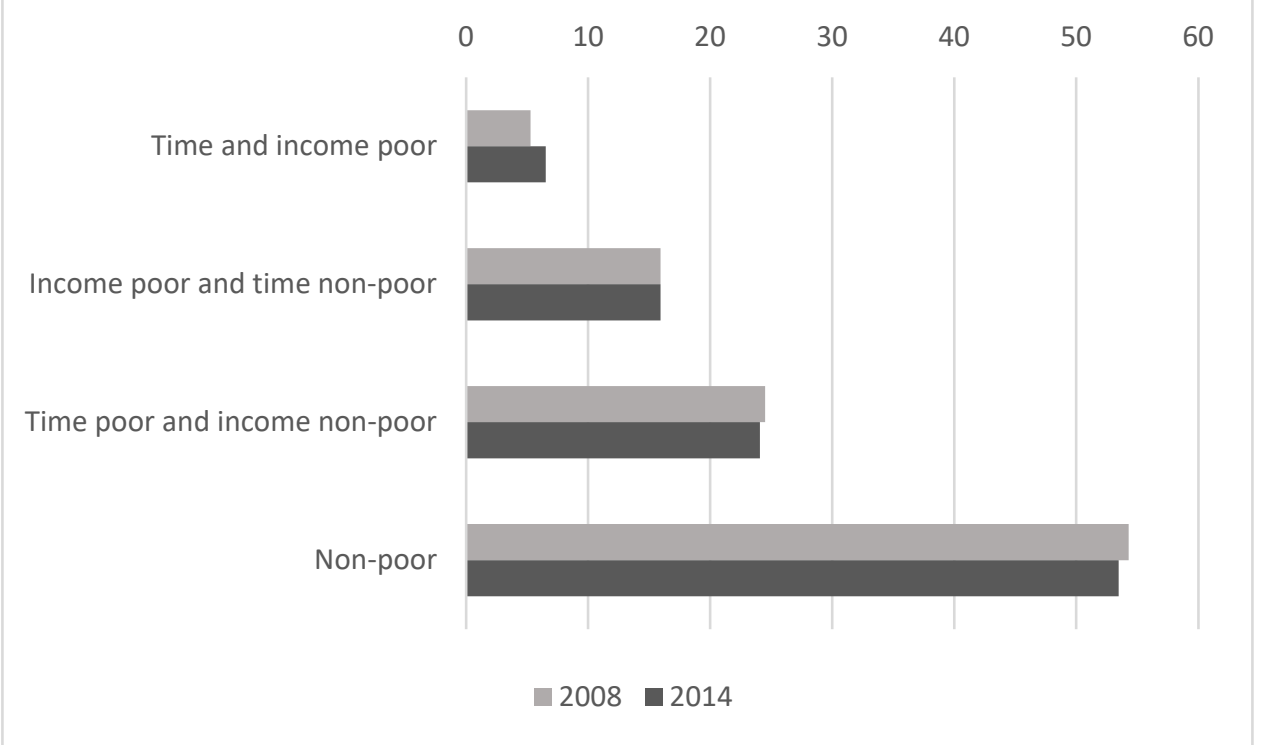

Source: Matched datasets

These firsts results highlight that using the LIMTIP allows for a more complex analysis of poverty that leaves broad space for research in developed contexts as well as in developing ones. 


\section{REFERENCES}

Kum, H., and T. Masterson. 2010. "Statistical matching using propensity scores : Theory and application to the analysis of the distribution of income and wealth." Journal of Economic and Social Measurement 35: 177-96.

Masterson, T. 2014. "Quality of Statistical Match and Employment Simulations Used in the Estimation of the Levy Institute Measure of Time and Income Poverty (LIMTIP) for South Korea, 2009." Levy Institute Working Paper No. 793. Annandale-on-Hudson, NY: Levy Economics Institute of Bard College.

Rubin, D. B., and N. Thomas. 1996. "Matching Using Estimated Propensity Scores: Relating Theory to Practice." Biometrics 52: 249-64.

Zacharias, A. 2011. "The Measurement of Time and Income Poverty." Levy Institute Working Paper No. 690. Annandale-on-Hudson, NY: Levy Economics Institute of Bard College.

Zacharias, A., R. Antonopoulos, and T. Masterson. 2012. "Why Time Deficits Matter: Implications for the Measurement of Poverty.” Research Project Report. Annandale-on-Hudson, NY: Levy Economics Institute of Bard College. August. 


\section{APPENDIX}

Figure A1: Ratio of Imputed Values to IT-TUS Values, Average by Number of Children and Sex (2008)

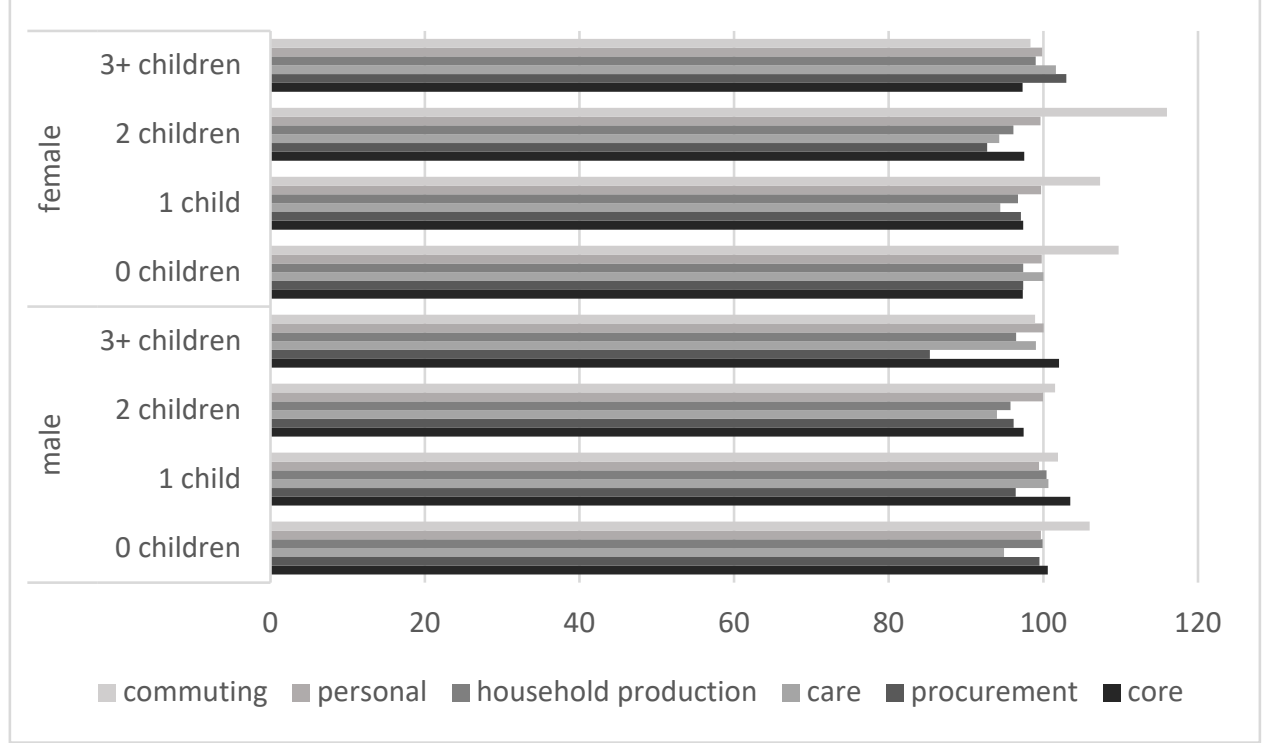

Figure A2: Ratio of Imputed Values to IT-TUS Values, Average by Number of Children and Sex (2014)

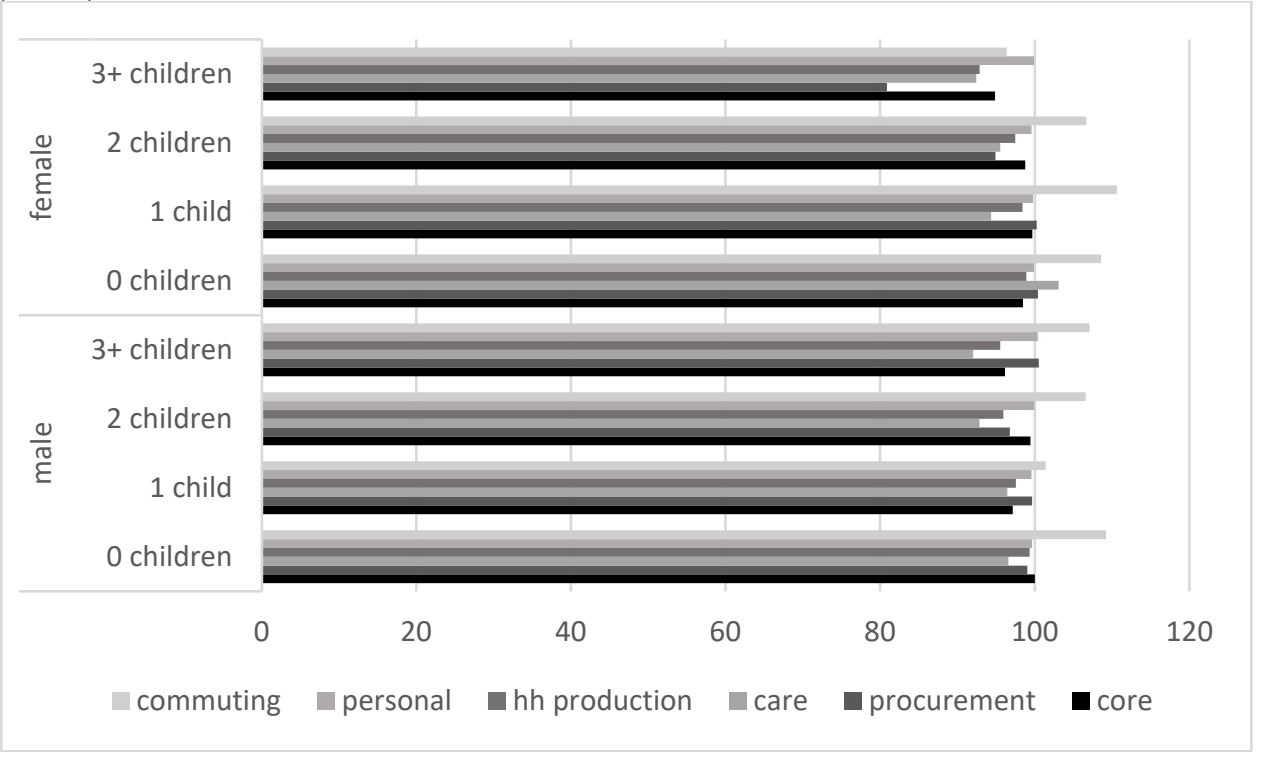


Figure A3: Distribution of Weekly Hours of Household Production by Cell (2008)

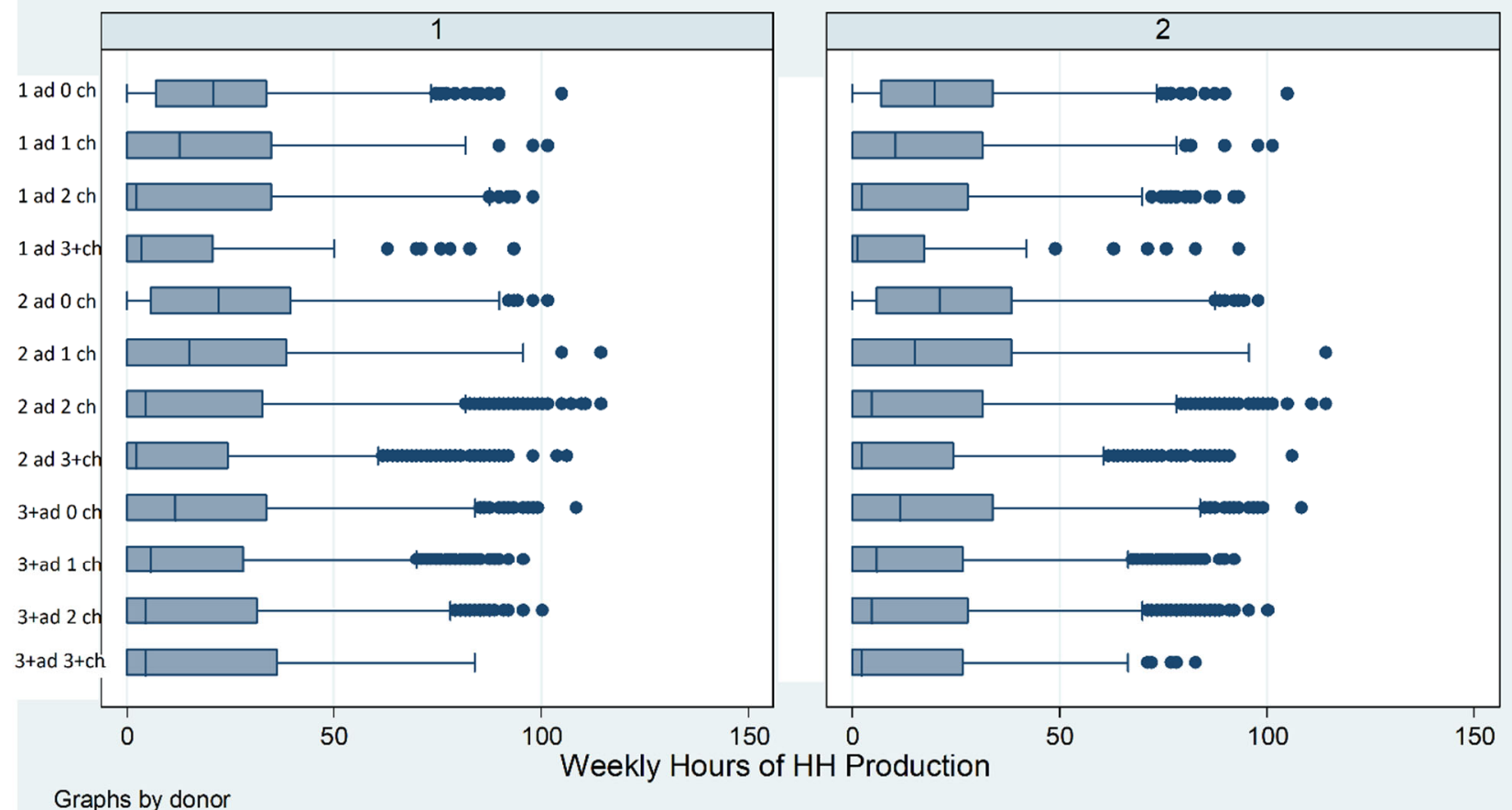

Figure A4: Distribution of Weekly Hours of Household Production by Cell (2014)

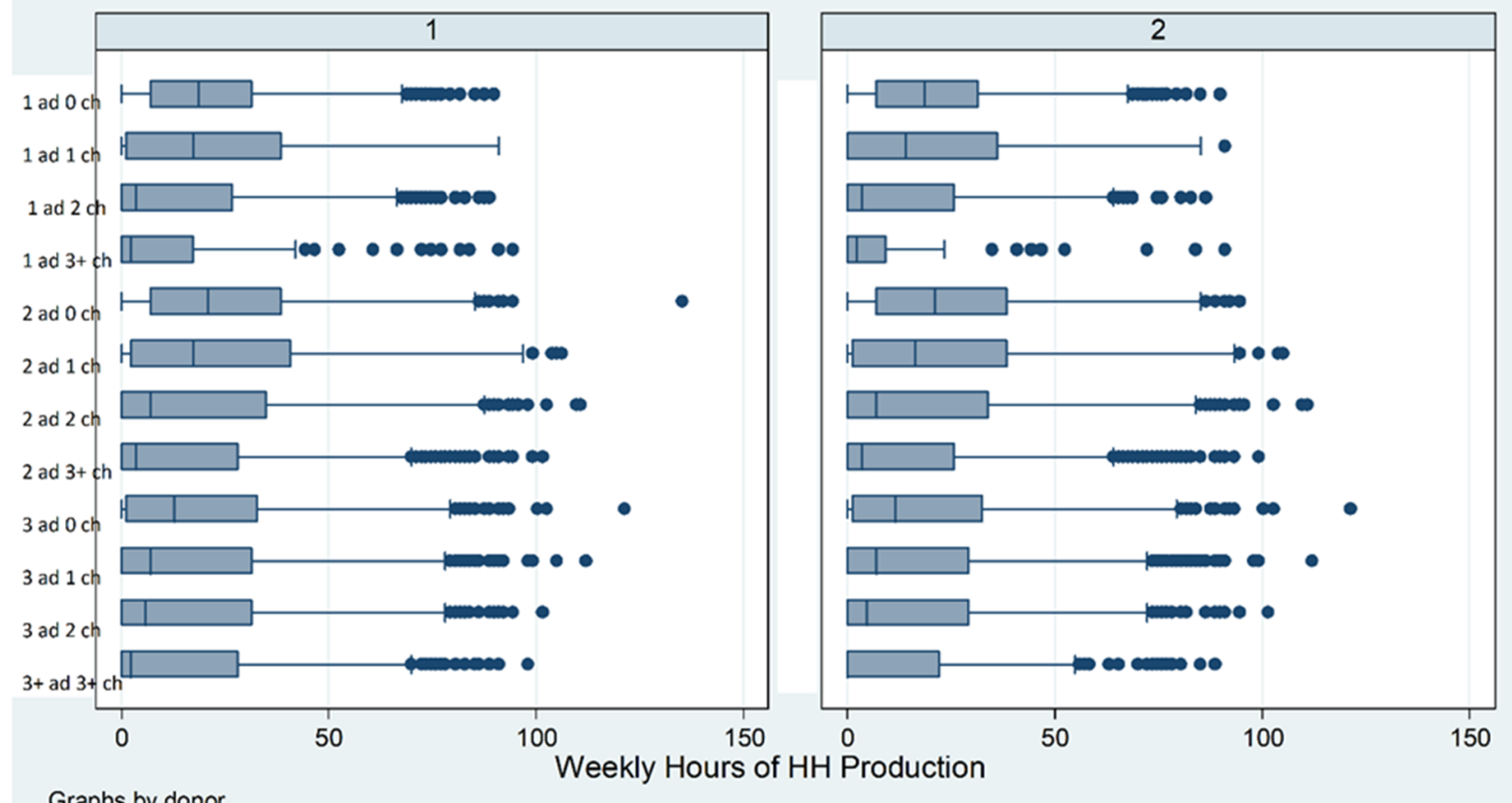

Graphs by donor 
Table A1: Alignment of Strata Variables (in percent, 2008)

\begin{tabular}{|c|c|c|c|}
\hline & IT-SILC & IT-TUS & Difference \\
\hline \multicolumn{4}{|l|}{ Number of adults } \\
\hline 1 & 14.58 & 13.47 & 1.11 \\
\hline 2 & 47.65 & 49.18 & -1.53 \\
\hline $3+$ & 37.77 & 37.35 & 0.42 \\
\hline \multicolumn{4}{|l|}{ Number of children } \\
\hline 0 & 58.89 & 57.77 & 1.12 \\
\hline 1 & 20.94 & 20.1 & 0.84 \\
\hline 2 & 16.5 & 17.78 & -1.28 \\
\hline $3+$ & 3.67 & 4.35 & -0.68 \\
\hline \multicolumn{4}{|c|}{ Presence of nonemployed adult in household } \\
\hline 0 & 16.12 & 14.55 & 1.57 \\
\hline 1 & 83.88 & 85.45 & -1.57 \\
\hline \multicolumn{4}{|c|}{ Presence of children younger than 3 years old } \\
\hline 0 & 91.18 & 89.9 & 1.28 \\
\hline 1 & 8.82 & 10.1 & -1.28 \\
\hline \multicolumn{4}{|l|}{ Main source of income } \\
\hline employment & 42.89 & 38.42 & 4.47 \\
\hline pension & 22.7 & 23.37 & -0.67 \\
\hline benefits & 3.05 & 1.97 & 1.08 \\
\hline family & 31.36 & 36.24 & -4.88 \\
\hline \multicolumn{4}{|l|}{ Activity status } \\
\hline working full time & 33.69 & 34.3 & -0.61 \\
\hline working part time & 4.18 & 5.29 & -1.11 \\
\hline unemployed, retired, inactive & 40.74 & 39.31 & 1.43 \\
\hline student & 16.08 & 15.29 & 0.79 \\
\hline preschool & 5.3 & 5.81 & -0.51 \\
\hline \multicolumn{4}{|c|}{ Number of earners in the household } \\
\hline 0 & 14.36 & 12.03 & 2.33 \\
\hline 1 & 27.76 & 25.39 & 2.37 \\
\hline 2 & 30.26 & 30 & 0.26 \\
\hline 3 & 27.63 & 32.58 & -4.95 \\
\hline \multicolumn{4}{|l|}{ Marital status } \\
\hline never married & 37.88 & 37.8 & 0.08 \\
\hline married & 47.5 & 46.83 & 0.67 \\
\hline separated/divorced & 2.92 & 4.8 & -1.88 \\
\hline widowed & 8.1 & 7.86 & 0.24 \\
\hline de facto & 3.59 & 2.71 & 0.88 \\
\hline \multicolumn{4}{|l|}{ Sex } \\
\hline male & 48.79 & 48.61 & 0.18 \\
\hline female & 51.21 & 51.39 & -0.18 \\
\hline
\end{tabular}


Table A2: Alignment of Strata Variables (in percent, 2014)

\begin{tabular}{|c|c|c|c|}
\hline & IT-SILC & IT-TUS & difference \\
\hline \multicolumn{4}{|l|}{ Number of adults } \\
\hline 1 & 15.83 & 15.57 & 0.26 \\
\hline 2 & 48.2 & 48.25 & -0.05 \\
\hline $3+$ & 35.97 & 36.18 & -0.21 \\
\hline \multicolumn{4}{|l|}{ Number of children } \\
\hline 0 & 60.67 & 58.39 & 2.28 \\
\hline 1 & 19.01 & 19.93 & -0.92 \\
\hline 2 & 16.00 & 16.97 & -0.97 \\
\hline $3+$ & 4.33 & 4.7 & -0.37 \\
\hline \multicolumn{4}{|c|}{ Presence of non-employed adult in household } \\
\hline 0 & 32.1 & 32.07 & 0.03 \\
\hline 1 & 67.9 & 67.93 & -0.03 \\
\hline \multicolumn{4}{|c|}{ Presence of children younger than 3 years old } \\
\hline 0 & 92.98 & 90.74 & 2.24 \\
\hline 1 & 7.02 & 9.26 & -2.24 \\
\hline \multicolumn{4}{|l|}{ Main source of income } \\
\hline employment & 41.69 & 35.46 & 6.23 \\
\hline pension & 18.28 & 23.07 & -4.79 \\
\hline benefits & 7.62 & 3.78 & 3.84 \\
\hline family & 32.4 & 37.7 & -5.30 \\
\hline \multicolumn{4}{|l|}{ Activity status } \\
\hline working full time & 30.93 & 30.45 & 0.48 \\
\hline working part time & 5.95 & 6.36 & -0.41 \\
\hline unemployed, retired, inactive & 41.74 & 41.47 & 0.27 \\
\hline student & 16.6 & 16.33 & 0.27 \\
\hline preschool & 4.77 & 5.39 & -0.62 \\
\hline \multicolumn{4}{|c|}{ Number of earners in the household } \\
\hline 0 & 27.94 & 28.16 & -0.22 \\
\hline 1 & 38.75 & 38.21 & 0.54 \\
\hline 2 & 28.43 & 27.91 & 0.52 \\
\hline 3 & 4.88 & 5.72 & -0.84 \\
\hline \multicolumn{4}{|l|}{ Marital status } \\
\hline never married & 38.01 & 38.29 & -0.28 \\
\hline married & 46.42 & 44.24 & 2.18 \\
\hline separated/divorced & 3.72 & 5.89 & -2.17 \\
\hline widowed & 8.23 & 7.83 & 0.40 \\
\hline de facto & 3.63 & 3.75 & -0.12 \\
\hline \multicolumn{4}{|l|}{ Sex } \\
\hline male & 48.58 & 48.55 & 0.03 \\
\hline female & 51.42 & 51.45 & -0.03 \\
\hline
\end{tabular}


Table A3: Distribution of Matched Records by Matching Rounds (2008)

\begin{tabular}{|c|c|}
\hline Round & $\begin{array}{c}\text { Matched } \\
\text { Individuals }\end{array}$ \\
\hline 1 & 47507008 \\
\hline 2 & 4752298 \\
\hline 3 & 258107 \\
\hline 4 & 1293644 \\
\hline 5 & 116548 \\
\hline 6 & 221074 \\
\hline 7 & 46196 \\
\hline 8 & 51037 \\
\hline 9 & 1658437 \\
\hline 10 & 1781008 \\
\hline 11 & 46940 \\
\hline 12 & 234829 \\
\hline 13 & 160003 \\
\hline 14 & 227897 \\
\hline 15 & 17540 \\
\hline 16 & 583261 \\
\hline 17 & 129776 \\
\hline 18 & 11514 \\
\hline 19 & 62401 \\
\hline 20 & 7603 \\
\hline 21 & 12594 \\
\hline 22 & 7655 \\
\hline 23 & 15285 \\
\hline 24 & 14371 \\
\hline 25 & 13143 \\
\hline 26 & 11899 \\
\hline 27 & 19597 \\
\hline 28 & 8740 \\
\hline 29 & 12089 \\
\hline 30 & 23471 \\
\hline 31 & 92779 \\
\hline 32 & 69632 \\
\hline 33 & 5752 \\
\hline 34 & 4514 \\
\hline Total & 59478642 \\
\hline
\end{tabular}


Table A4: Distribution of Matched Records by Matching Rounds (2014)

\begin{tabular}{|c|c|}
\hline Round & $\begin{array}{c}\text { Matched } \\
\text { Individuals }\end{array}$ \\
\hline 1 & 48646142 \\
\hline 2 & 3886754 \\
\hline 3 & 513977 \\
\hline 4 & 1297739 \\
\hline 5 & 130502 \\
\hline 6 & 235498 \\
\hline 7 & 72756 \\
\hline 8 & 92320 \\
\hline 9 & 1061537 \\
\hline 10 & 1048758 \\
\hline 11 & 116697 \\
\hline 12 & 304379 \\
\hline 13 & 235238 \\
\hline 14 & 203647 \\
\hline 15 & 51790 \\
\hline 16 & 2539570 \\
\hline 17 & 149019 \\
\hline 18 & 12070 \\
\hline 19 & 126672 \\
\hline 20 & 10161 \\
\hline 21 & 3624 \\
\hline 22 & 12809 \\
\hline 23 & 15132 \\
\hline 24 & 250 \\
\hline 25 & 2794 \\
\hline 26 & 7406 \\
\hline Total & 60777241 \\
\hline
\end{tabular}

Table A5: Average Weekly Hours of Household Production in IT-TUS and Matched File (2008)

\begin{tabular}{|l|r|r|r|r|r|r|}
\hline Survey & Core & Procurement & Care & \multicolumn{1}{l|}{$\begin{array}{l}\text { HH } \\
\text { Production }\end{array}$} & Personal & Commuting \\
\hline IT-TUS & 14.59 & 3.85 & 2.44 & 20.88 & 82.82 & 1.59 \\
\hline MATCH & 14.31 & 3.77 & 2.29 & 20.38 & 82.56 & 1.7 \\
\hline
\end{tabular}

Table A6: Average Weekly Hours of Household Production in IT-TUS and Matched File (2014)

\begin{tabular}{|l|r|r|r|r|r|r|}
\hline Survey & \multicolumn{1}{l|}{ Core } & Procurement & Care & \multicolumn{1}{l}{$\begin{array}{l}\text { HH } \\
\text { Production }\end{array}$} & Personal & Commuting \\
\hline IT-TUS & 13.91 & 3.95 & 3.04 & 20.9 & 83.86 & 1.41 \\
\hline MATCH & 13.81 & 3.94 & 2.82 & 20.57 & 83.65 & 1.51 \\
\hline
\end{tabular}


Table A7: Ratio of Imputed Values to IT-TUS Values by Strata Variable (2008)

\begin{tabular}{|c|c|c|c|c|c|c|}
\hline Variable & Core & Procurement & Care & $\begin{array}{l}\text { HH } \\
\text { Production }\end{array}$ & Personal & Commuting \\
\hline \multicolumn{7}{|l|}{ Number of children } \\
\hline 0 children & 97.69 & 98.02 & 98.36 & 97.78 & 99.76 & 107.74 \\
\hline 1 child & 98.27 & 96.54 & 96.41 & 97.55 & 99.57 & 104.04 \\
\hline 2 children & 97.04 & 93.92 & 93.94 & 95.62 & 99.80 & 105.84 \\
\hline $3+$ children & 92.66 & 93.87 & 98.01 & 94.41 & 99.89 & 102.50 \\
\hline \multicolumn{7}{|l|}{ Number of adults } \\
\hline 1 adult & 99.45 & 96.57 & 83.17 & 98.11 & 99.58 & 104.29 \\
\hline 2 adults & 98.15 & 98.40 & 97.08 & 98.01 & 99.86 & 105.84 \\
\hline $3+$ adults & 97.06 & 97.89 & 93.65 & 96.95 & 99.52 & 108.72 \\
\hline \multicolumn{7}{|c|}{ Presence of nonemployed adult } \\
\hline 0 & 100.00 & 99.71 & 92.02 & 98.48 & 99.53 & 99.60 \\
\hline 1 & 98.37 & 97.96 & 93.91 & 97.82 & 99.75 & 108.39 \\
\hline \multicolumn{7}{|l|}{ Activity status } \\
\hline working full time & 104.08 & 100.00 & 96.04 & 101.58 & 100.08 & 96.35 \\
\hline working part time & 104.10 & 100.65 & 96.93 & 102.25 & 99.61 & 96.91 \\
\hline $\begin{array}{l}\text { unemployed, retired, } \\
\text { inactive }\end{array}$ & 94.36 & 95.48 & 94.16 & 94.53 & 99.26 & $883.33^{*}$ \\
\hline student & 104.76 & 129.41 & 138.89 & 109.91 & 99.35 & $833.33^{*}$ \\
\hline preschool & 170.00 & 0.00 & $300.00 *$ & 185.71 & 99.33 & 0.00 \\
\hline \multicolumn{7}{|l|}{ Sex } \\
\hline male & 101.44 & 98.79 & 95.27 & 99.72 & 99.67 & 104.25 \\
\hline female & 97.87 & 97.48 & 93.33 & 97.35 & 99.69 & 111.01 \\
\hline \multicolumn{7}{|l|}{ Marital status } \\
\hline never married & 100.38 & 103.68 & 107.32 & 101.46 & 99.23 & 112.12 \\
\hline married & 96.87 & 96.81 & 91.13 & 96.02 & 99.88 & 108.24 \\
\hline separated/divorced & 108.52 & 104.27 & 88.68 & 105.74 & 99.40 & 101.80 \\
\hline widowed & 99.35 & 97.66 & 101.49 & 99.11 & 100.06 & 90.32 \\
\hline de facto & 102.92 & 105.24 & 95.80 & 101.69 & 99.72 & 79.60 \\
\hline \multicolumn{7}{|l|}{ Main source of income } \\
\hline employment & 103.90 & 98.75 & 93.75 & 100.94 & 99.99 & 97.32 \\
\hline pension & 102.08 & 99.39 & 93.62 & 101.28 & 100.05 & 71.43 \\
\hline benefits & 100.35 & 92.57 & 109.77 & 99.75 & 99.49 & 148.65 \\
\hline family & 90.24 & 88.21 & 84.52 & 89.26 & 100.22 & 71.43 \\
\hline \multicolumn{7}{|c|}{ Number of earners in the household } \\
\hline 0 & 95.74 & 97.41 & 101.68 & 96.25 & 99.08 & $975.00 *$ \\
\hline 1 & 94.11 & 95.82 & 97.52 & 94.80 & 99.30 & 121.88 \\
\hline 2 & 96.23 & 96.62 & 91.99 & 95.65 & 99.71 & 106.04 \\
\hline $3+$ & 98.85 & 99.46 & 95.63 & 98.53 & 99.88 & 103.24 \\
\hline \multicolumn{7}{|c|}{ Presence of children under 3 years old in the household } \\
\hline 0 & 97.90 & 98.20 & 98.15 & 97.93 & 99.69 & 106.45 \\
\hline 1 & 97.93 & 96.35 & 96.83 & 97.29 & 99.42 & 111.17 \\
\hline
\end{tabular}

Note: *Very high ratios are due to very small values. 
Table A8: Ratio of Imputed Values to IT-TUS Values by Strata Variable (2014)

\begin{tabular}{|c|c|c|c|c|c|c|}
\hline Variable & Core & Procurement & Care & $\begin{array}{l}\text { HH } \\
\text { Production }\end{array}$ & Personal & Commuting \\
\hline \multicolumn{7}{|l|}{ Number of children } \\
\hline 0 & 98.74 & 99.57 & 100.00 & 98.98 & 99.78 & 108.39 \\
\hline 1 & 98.23 & 100.00 & 94.59 & 97.41 & 99.69 & 104.97 \\
\hline 2 & 99.61 & 95.70 & 94.94 & 97.50 & 99.75 & 105.79 \\
\hline $3+$ & 94.63 & 89.59 & 92.05 & 93.23 & 100.15 & 105.56 \\
\hline \multicolumn{7}{|l|}{ Number of adults } \\
\hline 1 & 99.13 & 101.79 & 89.61 & 98.92 & 100.25 & 96.10 \\
\hline 2 & 99.72 & 97.97 & 94.02 & 98.30 & 99.95 & 103.05 \\
\hline $3+$ & 98.71 & 101.26 & 89.95 & 98.38 & 99.22 & 118.37 \\
\hline \multicolumn{7}{|c|}{ Presence of nonemployed adult } \\
\hline 0 & 100.96 & 101.76 & 96.46 & 100.11 & 99.98 & 97.54 \\
\hline 1 & 98.72 & 99.05 & 90.38 & 97.77 & 99.63 & 120.88 \\
\hline \multicolumn{7}{|l|}{ Activity status } \\
\hline working full time & 100.49 & 101.88 & 96.10 & 99.78 & 100.09 & 98.07 \\
\hline working part time & 102.39 & 100.23 & 87.80 & 99.01 & 100.46 & 95.96 \\
\hline $\begin{array}{l}\text { unemployed, } \\
\text { retired, inactive }\end{array}$ & 98.32 & 97.89 & 91.55 & 97.59 & 99.41 & $315.38^{*}$ \\
\hline student & 110.16 & 119.30 & 96.30 & 108.63 & 99.74 & $533.33^{*}$ \\
\hline preschool & 107.69 & 100.00 & 105.41 & 107.89 & 99.55 & 100.00 \\
\hline \multicolumn{7}{|l|}{ Sex } \\
\hline male & 100.36 & 99.72 & 93.03 & 98.70 & 99.69 & 107.07 \\
\hline female & 99.12 & 100.00 & 92.78 & 98.51 & 99.80 & 108.00 \\
\hline \multicolumn{7}{|l|}{ Marital status } \\
\hline never married & 103.19 & 104.81 & 88.62 & 101.66 & 99.55 & 112.93 \\
\hline married & 98.10 & 97.95 & 93.54 & 97.32 & 99.72 & 109.49 \\
\hline separated/divorced & 105.30 & 103.75 & 82.59 & 102.13 & 99.44 & 95.93 \\
\hline widowed & 96.23 & 101.52 & 143.75 & 97.99 & 99.81 & 155.00 \\
\hline de facto & 101.57 & 100.80 & 88.98 & 97.91 & 100.09 & 99.21 \\
\hline \multicolumn{7}{|c|}{ Main source of income } \\
\hline employment & 104.26 & 101.40 & 92.97 & 101.24 & 100.29 & 94.37 \\
\hline pension & 98.53 & 100.60 & 85.22 & 98.33 & 100.01 & 75.00 \\
\hline benefits & 103.85 & 99.12 & 71.64 & 99.58 & 99.35 & 94.87 \\
\hline family & 95.29 & 90.29 & 81.72 & 92.37 & 100.42 & 64.71 \\
\hline \multicolumn{7}{|c|}{ Number of earners in the household } \\
\hline 0 & 99.79 & 100.44 & 89.31 & 99.19 & 99.51 & $254.55^{*}$ \\
\hline 1 & 97.73 & 98.72 & 90.57 & 96.68 & 99.88 & 108.88 \\
\hline 2 & 101.53 & 100.28 & 96.87 & 100.27 & 99.73 & 100.00 \\
\hline $3+$ & 97.46 & 102.12 & 73.71 & 95.87 & 100.00 & 102.28 \\
\hline \multicolumn{7}{|c|}{ Presence of children under 3 years old } \\
\hline 0 & 99.07 & 99.49 & 98.21 & 99.06 & 99.73 & 108.63 \\
\hline 1 & 100.08 & 103.46 & 101.73 & 101.25 & 99.72 & 96.84 \\
\hline
\end{tabular}

Note: *Very high ratios are due to very small values. 